Scientific Journal. ISSN 2595-9433

Volume 1, Number 2, Article n. 5, November/December

D.O.I. http:// dx.doi.org/10.35418/2526-4117/v1n2a5

Accepted: 15/12/2018 Published: 02/12/19

\title{
REPETIBILITY IN GUAVA: HOW MANY EVALUATIONS IS NECESSARY FOR SELECTION THE BEST GUAVA TREE?
}

\author{
Claudia Lougon Paiva de Almeida ${ }^{1}$, Alexandre Pio Viana ${ }^{1}$, \\ Eileen Azevedo Santos ${ }^{1}$, Silvana Silva Red Quintal ${ }^{1}$
}

${ }^{1}$ Universidade Estadual do Norte Fluminense Darcy Ribeiro (UENF), Centro de Ciências e Tecnologias Agropecuárias, Av. Alberto Lamego, 2000, Parque Califórnia, 28013-600, Campos dos Goytacazes, RJ-Brazil.

Correspondent author: Eileen Azevedo Santos (eileenazevedo@yahoo.com.br)

\begin{abstract}
In fruit breeding, especially in the case of perennial species, is questioned what the ideal number of evaluations. The objective main of the present study was to estimate what the best number of harvest to be evaluation and select productive genotypes, with good adaptability and stability, by method of harmonic mean of the relative performance of predicted genetic values (HMRPGV), for production related traits by mixed models. We evaluated ten fullsib progenies, over four harvests, for fruit weight, number of fruits per plant, and total yield. Five predicted measurements from the same individual were sufficient for the selection of promising guava genotypes in the early stages of the breeding program. The genetic gain predicted for the 30 best individuals was higher than that achieved with the progeny. These genotypes can be used both as parents in new crosses and in the recommendation of clonal propagation for conventional planting, since there was a significance increase in yield.
\end{abstract}

keywords: Psidium guajava, guava breeding, mixed models

\section{Introduction}

Known in many places as 'the tropical apple', guava is the fruit of greatest value of the Myrtaceae family (Dhara et al., 2016). Originally from Tropical America (Kanwal et al., 2016), it can be found in many tropical and subtropical countries. Brazil stands out as the third largest guava producer and the largest producer of red guava in the world. To increase yields must be selected productive genotypes with precision. Therefore, it is necessary the evaluation of multiple harvests for promising genotypes to be selected with greater precision. However, perennial species, like guava, have some peculiarities that may generate problems in breeding program, e.g., it need for an enormous experimental area, long production cycle.

Much research has been undertaken to prove the importance of the effect of years on perennial crops, e.g., heart palm (Rodrigues et al., 2017) and citrus (Imai et al., 2016). According to these studies, to select promising genotypes with greater efficiency, it is more advantageous to increase the number of years and locations assessed than the number of progenies. The approach that best applies to the study of perennial species is restricted maximum likelihood (RML) and best linear unbiased prediction (BLUP) by the mixed- models methodology, because they provide an estimate of the variance components and the prediction of genetic values of the individual, respectively (Resende et al., 2016). The use of mixed models has been adopted in many perennial species, e.g., guava (Quintal et al., 2017), Annona muricata (Sanchéz et al., 2017), and eucalyptus (Vismara et al., 2015).

Given the above described scenario, the present study aimed to estimate the repeatability components of production-related traits in guava in order to determine the minimum number of evaluations necessary to identify superior guava genotypes; determine the adaptability and stability of progenies; predict genetic gains; and select the best families and individuals within guava families. 


\section{Material and methods}

\section{Breeding population}

The experiment was conducted in Campos dos Goytacazes, RJ, Brazil, involving 12 full-sib progenies evaluated in a complete-block design with 12 plants per plot, represented in two blocks. These families were obtained from the cross of parents diverging at molecular level. Seedlings were planted in 2008. Two harvests were evaluated in 2012, one in 2013, and another in 2014. It were evaluated in four annual harvests 119 individuals.

\section{Evaluated traits}

It were made observations at individual level for each one of the four harvests, in which number of fruits per plant $(\mathrm{NF})$, fruit weight $(\mathrm{FW})$, and total yield (TY) were evaluated. It was counted the number of fruits (NF) in each individual from the start of fructification to the end of the harvest. The fruit weight (FW) was determined by sampling 10 fruits per plant using an analytical balance, with results expressed in grams. The total yield of the individuals (TY) was obtained by multiplying the total number of fruits and fruit weight, and was expressed in grams.

\section{Mixed models analysis}

For these traits was analyzed deviance analysis, genetic parameters and genetic gains were estimated and predicted by the mixed models. Besides that genotype adaptability and stability was analyzed.

Genetic values were predicted using the mixedmodels approach, adopting a model according to the equation described below:

$$
y=X m+Z a+W p+Q i+T s+e(E q .1)
$$

Where $y$ is the vector of data, mis the vector of the effects of measurement replicate combinations (assumed fixed) added to the overall mean, $a$ is the vector of individual additive genetic effects (assumed random), $p$ is the vector of plot effects (random), $I$ is the vector of the genotype $\times$ measurement interaction effects (random), $s$ is the vector of permanent effects (random), $e$ is the vector of errors or residuals (random). $X$ is the incidence matrix of fixed effects; $Z$ is the incidence matrix of individual genetic effects, $W$ the incidence matrix of plot effects, $Q$ the incidence matrix of genotype $\times$ measurement effects, and $T$ the incidence matrix of permanent effects. Vector $m$ comprises all measurements in all replicates and simultaneously adjusts them for the effects of replicates, measurements, and replicate $\times$ measurement interaction.

The mixed-model equations were given by:

$$
\left[\begin{array}{ccccc}
X^{\prime} X & X^{\prime} Z & X^{\prime} W & X^{\prime} Q & X^{\prime} T \\
Z^{\prime} X Z^{\prime} Z+A^{-1} \lambda_{1} & Z^{\prime} W & Z^{\prime} Q & Z^{\prime} T \\
W^{\prime} X & W^{\prime} Z & W^{\prime} W+I \lambda_{2} & W^{\prime} Q & W^{\prime} T \\
Q^{\prime} X & Q^{\prime} Z & Q^{\prime} W & Q^{\prime} Q+I \lambda_{3} & Q^{\prime} T \\
T^{\prime} X & T^{\prime} Z & T^{\prime} W & T^{\prime} Q & T^{\prime} T+I \lambda_{4}
\end{array}\right]\left[\begin{array}{c}
\hat{m} \\
\hat{a} \\
\hat{p} \\
\hat{i} \\
\hat{s}
\end{array}\right]=\left[\begin{array}{c}
X^{\prime} y \\
Z^{\prime} y \\
W^{\prime} y \\
Q^{\prime} y \\
T^{\prime} y
\end{array}\right]
$$

Where

$$
\begin{aligned}
& h^{2}=\frac{\sigma_{g}^{2}}{\sigma_{a}^{2}+\sigma_{p}^{2}+\sigma_{i}^{2}+\sigma_{s}^{2}+\sigma_{e}^{2}}, \text { individual heritability; } \\
& p=\frac{\sigma_{c}^{2}}{\sigma_{a}^{2}+\sigma_{p}^{2}+\sigma_{i}^{2}+\sigma_{s}^{2}+\sigma_{e}^{2}}, \quad, \text { coefficient of determination }
\end{aligned}
$$
of plot effects;

$$
\begin{array}{ll}
i=\frac{\sigma_{i}^{2}}{\sigma_{a}^{2}+\sigma_{p}^{2}+\sigma_{i}^{2}+\sigma_{s}^{2}+\sigma_{e}^{2}}, & , \text { coefficient of determination } \\
& \text { of genotype } \times \text { measurement } \\
& \text { interaction effects; } \\
s=\frac{\sigma_{s}^{2}}{\sigma_{a}^{2}+\sigma_{p}^{2}+\sigma_{i}^{2}+\sigma_{s}^{2}+\sigma_{e}^{2}} & , \text { coefficient of determination }
\end{array}
$$

of permanent effects; and

A: matrix of additive genetic relatedness among the individuals.

According to the described model, deviance analysis was obtained as follows:

$$
\mathrm{D}=-2 \ln (\mathrm{L})
$$

$$
\ln (\mathrm{L})=-1 / 2 \ln \left|\mathrm{X}^{\prime} \mathrm{V}^{-1} \mathrm{X}\right|-1 / 2 \ln |\mathrm{V}|-1 / 2(\mathrm{y}-\mathrm{Xm})^{\prime} \mathrm{V}^{-1}(\mathrm{y}-\mathrm{Xm})
$$

Where $\ln (\mathrm{L})$ is the maximum point of the restricted maximum likelihood (REML) logarithm function (Lopes et al. 2014); y is the vector of the analyzed variable; $m$ is the vector of effects of measurements, assumed fixed, with all means added; $\mathrm{X}$ is the incidence matrix for the fixed effects; and V is the variance-covariance matrix of $y$.

The LRT (likelihood ratio test) statistical test used to test the significance of the effects, as follows:

$$
\text { LRT: } \mid-2 \ln \left(\mathrm{L}_{\mathrm{se}}\right)+2 \ln \left(\mathrm{L}_{\mathrm{fm}}\right)
$$

Where $\mathrm{L}_{\mathrm{sc}}$ is the maximum point of the maximum likelihood function for the reduced model (without the effects), and $\mathrm{L}_{\mathrm{fm}}$ is the maximum point of the maximum likelihood function for the full model.

The variance components for the calculation of the repeatability coefficient estimated through the restricted maximum likelihood (REML) procedure. Repeatability at plot level $(\rho)$ estimated as follows:

$$
\begin{gathered}
\rho=\frac{V_{g}+V_{\text {perm }}}{V p} \\
\rho=\frac{\sigma_{a}^{2}+\sigma_{p}^{2}+\sigma_{i}^{2}+\sigma_{s}^{2}}{\sigma_{a}^{2}+\sigma_{p}^{2}+\sigma_{i}^{2}+\sigma_{s}^{2}+\sigma^{2}}
\end{gathered}
$$


Where $\mathrm{V}_{\mathrm{g}}$ is the genetic variance among plants, $\mathrm{V}_{\text {perm }}$ is the variance of permanent effects, and $\mathrm{V}_{\mathrm{p}}$ is the phenotypic variance.

We also estimated the broad-sense heritability at individual level $\left(\mathrm{h}_{\mathrm{g}}^{2}\right)$; i.e., the heritability of genotypic effects the coefficient of determination of permanent effects $\left(\mathrm{c}^{2}\right.$ perm $)$; the coefficient of determination of plot effects $\left(\mathrm{c}^{2}\right.$ plot $)$; the coefficient of determination of genotype $\times$ harvest interaction effects $\left(\mathrm{c}^{2}{ }_{\mathrm{gm}}\right)$; the genetic determination $\left(\mathrm{R}_{2}\right)$; and the selection accuracy after several measurements.

Stability was estimated by the HMGV (harmonic mean of genetic values) method:

$$
H M G V=\frac{n}{\sum_{j=1}^{n}\left(\frac{1}{V g_{i j}}\right)}
$$

Where $\mathrm{n}$ represents the number of environments, or harvests ( $\mathrm{n}=4$ harvests), $\mathrm{i}$ is the evaluated genotype, and $\mathrm{Vg}_{\mathrm{ij}}$ is the value of genotype $\mathrm{i}$ in environment $\mathrm{j}$. Adaptability was measured by the RPGV (relative performance of genotypic values) values, according to the following expression:

$$
R P G V=\frac{1}{n} x\left(\frac{\sum_{j=1}^{n} V g_{i j}}{M_{j}}\right)
$$

Where $\mathrm{M}_{\mathrm{j}}$ is the mean of the analyzed variable (fruit weight, number of fruits, and yield) in environment $\mathrm{j}$.

By the HMRPGV (harmonic mean of predicted genetic values) method, the best individuals within each progeny that stood out were selected, based on three aspects. First, selection based on the predicted genetic value considering the average performance in all harvests (without interaction effect). Second, selection based on the predicted genetic value considering the average performance in each harvest (with the mean interaction effect). In addition, the last, without interaction effect; and simultaneous selection for yield, stability (HMGV), and adaptability (RPGV). This selection is given by:

$$
\text { HMRPGV }=\frac{n /\left(\sum_{j=1}^{n} \times 1\right)}{V g_{i j}}
$$

SELEGEN computer software was used for the REML/BLUP approach and for adaptability and stability (Resende, 2016). The 30 most promising genotypes for each trait were selected.

\section{Results and discussion}

\section{Genetic parameter estimate}

Breeders seek to select genotypes as competitive as the recommended cultivars. The population evaluated in this study produces on average 90 fruits per plant, with fruit weight approximately $187 \mathrm{~g}$. These results are similar to those found for guava cultivar 'Paluma', which produces approximately 188 fruits per plant, with a fruit weight of $140 \mathrm{~g}$, which is lower than that observed in the present study (Rocha et al., 2016). This indicates that the studied population is promising; however, for total fruit yield to be increased, the number of fruits must also be higher.

Deviance analysis revealed that progeny effects were only significant for total yield (Table 1). By contrast, for all analyzed variables, the genotype $x$ harvest interaction was highly significant.

The phenotypic variance was decomposed into genetic variance, variance of the genotype $x$ measurement interaction, variance of permanent effects, and temporary residual variance. The contribution of genetic variance was low, with environmental effects predominating, especially the temporary effects (Table 2). Consequently, the individual heritability obtained for the studied variables was of low magnitude; however, the lowest values were found for fruit weight (Table 2).

The estimation of variance components from the mixed model (REML/BLUP) indicated that the environmental variance predominated in the phenotypic variance, suggesting that the environmental variance from one year to another was important, since the variables evaluated here are quantitative, controlled by genes of low effect, and highly influenced by the environment. The fact that perennial young plants were used is another factor that leads to predominance of environmental variance, because plants are subjected to different annual inclement weather conditions, which contributes for phenotypic potentials to be expressed differently over the years.

The genotype $\times$ measurement interaction effects and the coefficient of determination of the permanent effects explained approximately $11 \%$ of the total variation in harvests of individual plants for all variables. As expected for quantitative variables, the repeatability coefficient for the studied variables had a low magnitude: $0.14,0.27$, and 0.24 for fruit weight, number of fruits, and total yield, respectively (Table 2). The predominance of environmental effects corroborated for the genotype $\times$ harvest interaction to be highly significant, as can be verified in the deviance analysis. This generates a problem to the breeder, since there is little coincidence among the best genotypes in the evaluated harvests. Therefore, a model that comprises this genotype $\times$ harvest interaction should be adopted, indicating the promising genotypes precisely. 
Deviance analysis also showed that there were significant differences between genotypes only for the total yield, with possibilities of genetic gains through the selection of superior individuals for this variable.

The determination coefficient or individual heritability values were of low magnitude. The high values for environmental variance provided low individual heritability estimates, with fruit weight being the variable with the lowest estimate. In addition to the high influence of the environment in the expression of production related traits, the low magnitude of heritability may also be associated with the narrow genetic base of the population, which consisted of full siblings.

Low and medium magnitude values for heritability are expected, especially in the case of perennial species, which are susceptible to climatic variations over the years. Mixed modeling (REML/ BLUP) allows for optimal estimates even with low heritability values, which did not aggravate the results. This approach considers the random effects of the statistical model associated with phenotypic observations and adjusts the data to the fixed effects and to the unequal amount of information in the plot, which allows data to be corrected, minimizing environmental effects (Figueiredo et al., 2015). This makes it possible for problems of data imbalance - as found in the present study, like plots with different number of plants to be properly corrected, thereby contributing to the development of guava breeding.

Data analysis involving many crop years allows for an estimate of the repeatability coefficient; through this estimate, it is possible to predict how many evaluations will be necessary for selection with greater reliability. The estimated heritability, individual repeatability, and genotypic correlation parameters throughout harvests are essential for the breeder to select superior individuals.

According to the estimate provided by BLUP for the 12 harvests, there was a significant increase in heritability between families average for all evaluated traits. For this harvest, the genetic determination from 0.26 to 0.64 in number of fruits, and from 0.24 to 0.61 in total yield up to the fifth harvest, which led to greater elevations in accuracy and efficiency (Table 3 ). However, from the fifth evaluation onwards, the increments were low. By contrast, for fruit weight, increases were lower from the ninth evaluation (Table $3)$.

The repeatability coefficients found in this study were of low magnitude. According to Resende (2016), coefficients equal to or lower than 0.30 are considered low. Low repeatability values indicate, requiring a larger number of evaluations of the same that the performance of individuals is not continuous individual to achieve optimal genotypic determination values. This agrees with the prediction of values for genotypic determination, accuracy, and efficiency of repeated measures estimated by BLUP in this study.

From the fifth harvest on, there was a predicted increase in genetic determination and selection accuracy for total yield and number of fruits, respectively, indicating that at least five measurements for number of fruits and total fruit yield are necessary for a reliable genotype selection. Thus, if another evaluation is performed on this population, the probability of selecting guava genotypes of high agronomic performance will be significantly heightened. By contrast, for the fruit weight variable an increase of 0.60 in genetic determination was observed only after the tenth evaluation, suggesting that selection aimed at this variable requires several observations.

Rodrigues et al. (2017) evaluated the population of heart palm for five years and found low repeatability, and recommended seven measurements for yield. Sanchéz et al. (2017) found that eight crop season for Annona muricata are necessary for an effective selection.

As regards the repeatability estimates, lowmagnitude values were observed in perennial plants, such as citrus (Imai et al., 2016) and almonds (Laviola et al., 2013), which suggests that several assessments are necessary in perennial species, especially for production related variables. This is because several genic groups that are expressed in various plant stages determine fruit production. According to Laviola et al. (2013), perennial plants present good stability after the fourth year of harvest. Thus, when the repeatability of not yet stabilized genotypes is analyzed, it is common to obtain low-magnitude repeatability values.

Several factors influence selection accuracy, among which are heritability, the repeatability of the trait, and quality of information and procedures employed in the estimation of genetic values. Higher accuracy increases reliability at selection and in the predicted genetic value, which allows for the selection of promising genotypes with greater precision. The low heritability and repeatability estimates might have contributed to medium selection-accuracy values. However, they were effective in indicating the minimum number of evaluations to be performed on the population. With five measurements predicted for fruit yield, the selection accuracy was 53, with a determination coefficient of around $62 \%$, which is appropriate for the initial stage of the breeding program in crop fruit.

\section{Selection the best families and individuals within guava families in four harvests}

Considering the five most promising progenies, the predicted genetic gains were satisfactory for number of fruits (11 to $18 \%$ ) and total yield (12 to $22 \%$ ). However, for fruit weight, the estimated gains were low, and the best progeny obtained a gain of $0.52 \%$ 
(Table 4). The best progenies selected for number of fruits were also selected for total yield. However, the progenies that obtained good results for fruit weight differed from each other, only progeny 10 was selected for number of fruits and total yield, ranking last for weight and number of fruits (Table 4).

Despite the low heritability estimates, considerable gains were obtained with the selection of the five best progenies. The gains predicted for total yield and number of fruits was favorable, ranging from 12 to $22 \%$ and 12 to $18 \%$, respectively. The fruit weight variable did not achieve satisfactory gains. Thus, selection of individuals with a greater number of fruits, and also more productive, should be prioritized, since the original mean referring to the fruit weight of the population (184 g) is higher than that of cultivar 'Paluma' (140 g) (Rocha et al., 2016). With an increase in yield, the population under study will be as productive as 'Paluma', the cultivar present on most guava farms.

There was agreement in the ranking of the most productive progenies according to the adaptability (PRVG) and stability (MHVG) criteria, both criteria simultaneously (MHPRVG) (Table 5), and by the genetic mean without interaction $(\mathrm{u}+\mathrm{g})$. According to the adaptability (RPGV) and stability (HMGV) criteria and the simultaneous selection method based on the production performance of the genotypes (HMRPGV), there was agreement in the ranking of progenies selected for number of fruits and total yield. This indicates that the selected progenies showed adaptability and stability, in addition to a high yield, i.e., these attributes predominated throughout the many crop years.

On the other hand, progenies that stand out for fruit weight differed from the most promising ones with respect to number of fruits and total yield. This demonstrates that there is a negative correlation between fruit weight and number of fruits, i.e., plants producing a larger number of fruits have a lower weight. However, selection of different progenies for fruit weight is not a problem for this population, since the entire population already has a satisfactory average weight.

As stated by Torres et al. (2016) the selection of progenies considering adaptability and stability estimates of genotypes enables a more refined recommendation of progenies. The REML/BLUP method generates results that are explained directly as genotypic values, already penalized or capitalized by the stability and adaptability estimates (Resende, 2016).

Genetic gains predicted for individuals were substantially higher as compared with the gains predicted for the progenies. For all variables, the 30 best individuals were selected, and promising progenies were maintained. At individual level, gains were higher as compared with the mean of progenies for all variables. For number of fruits, there was a predicted gain of 125.60 to $262.06 \%$ fruits. For fruit weight, the gain ranged from 25.96 to $43.76 \%$. Consequently, there was an increase in total yield ranged from 113.58 to $176.46 \%$ with a twice-higher mean than the mean of the progenies, for all genotypes selected. The additive value predominated over the dominance deviations in all variables.

Santos et al. (2015) also found high gain values for individuals of a population obtained from an interspecific cross in Passiflora. Individual gains predicted by BLUP are usually higher than those obtained based on the mean of progenies, because it is based on the genetic value of the individual rather than on the mean of the progeny. Another important finding in the individual analysis is the fact that the additive value was greater than the dominance value, suggesting that these traits are transmitted onto the offspring, since additive values are relative to the alleles responsible for the transmission of traits.

For the guava crop, clonal propagation is preferred over seed propagation, as the former provides the maintenance of fruit quality and greater yields in a short time frame (Kareemet al., 2013). Moreover, when individual selection is performed considering the vegetative propagation, all genetic variance can be exploited, fully maintaining its genome (Maia et al., 2009). In this way, the 30 best genotypes selected in this study have the potential to be used as parents in new crosses, ensuring the continuity of the breeding program, as well as to be cloned for VCU trials aimed at the release of a new guava cultivar.

Table 1. Deviance analysis for number of fruits, fruit weight, and total yield in full-sibling $P$. guajava families evaluated in four harvests.

\begin{tabular}{ccccccc}
\hline & \multicolumn{2}{c}{ NF } & \multicolumn{2}{c}{ FW $(\mathrm{g})$} & \multicolumn{2}{c}{ TY $(\mathrm{kg})$} \\
\hline Source & Dev & LRT & Dev & LRT & Dev & LRT \\
\hline Genotype & 4172.51 & 1.36 & 3944.45 & 0 & 8827.24 & $3.21^{*}$ \\
Plot & 4173.88 & 2.73 & 3946.23 & 1.77 & 8824.59 & 0.56 \\
Genotype $\times$ Measurement & 4192.58 & $21.43^{* *}$ & 3962.25 & $17.79^{* *}$ & 8845.47 & $21.44 * *$ \\
Permanent environment & 4185.4 & $14.25^{* *}$ & 3951.28 & $6.82^{* *}$ & 8836.34 & $12.31^{* *}$ \\
Full model & 4171.15 & & 3944.46 & & 8824.03 & \\
\hline
\end{tabular}

NF: number of fruit; FW: Fruit Weight; TY: Total Fruit Yield *significant at 5\%, **significant at 1\%. 
Table 2. Variance components obtained by individual REML for fruit weight (FW), number of fruits per plant (NF), and total fruit yield (TY) in full-sibling P. guajava families evaluated in four harvests.

\begin{tabular}{cccc}
\hline \multicolumn{4}{c}{ Variance components } \\
\hline & $\mathrm{FW}(\mathrm{g})$ & $\mathrm{NF}$ & $\mathrm{TY}(\mathrm{kg})$ \\
\hline $\mathrm{V}_{\mathrm{g}}$ & 9.012003 & 283.3005 & 8295665 \\
$\mathrm{~V}_{\text {plot }}$ & 87.73124 & 177.5566 & 1408524 \\
$\mathrm{~V}_{\mathrm{gm}}$ & 220.5743 & 377.8456 & 7963166 \\
$\mathrm{~V}_{\text {perm }}$ & 177.6396 & 422.2458 & 8874334 \\
$\mathrm{~V}_{\mathrm{e}}$ & 1387.565 & 2130.176 & 49195395 \\
$\mathrm{~V}_{\mathrm{f}}$ & 1882.522 & 3391.124 & 75737083 \\
$\mathrm{~h}^{2} \mathrm{~g}$ & 0.004787 & 0.083542 & 0.109532 \\
$\mathrm{c}^{2}{ }_{\text {plot }}$ & 0.046603 & 0.052359 & 0.018598 \\
$\mathrm{c}^{2}{ }_{\mathrm{gm}}$ & 0.11717 & 0.111422 & 0.105142 \\
$\mathrm{c}^{2}{ }_{\text {perm }}$ & 0.094363 & 0.124515 & 0.117173 \\
$\mathrm{r}$ & 0.145753 & 0.260416 & 0.245303 \\
$\mathrm{r}_{\text {gmsm }}$ & 0.039253 & 0.428499 & 0.510225 \\
\hline Overall mean & 187.0327 & 90.9197 & 15835.64 \\
\hline
\end{tabular}

$\mathrm{V}_{\mathrm{g}}$ : genotypic variance between progenies ( $1 / 4$ of the additive variation); $\mathrm{V}_{\text {plot }}:$ environmental variance between plots; $\mathrm{V}_{\mathrm{gm}}: \mathrm{variance}$ of the genotype $\times$ measurement interaction; $\mathrm{V}_{\text {perm }}$ : variance of permanent effects; $\mathrm{V}_{\mathrm{e}}$ : temporary residual variance; $\mathrm{V}_{\mathrm{f}}$ : individual phenotypic variance; $\mathrm{h}_{\mathrm{g}}^{2}=\mathrm{h}_{2}$ : heritability between progenies at individual level; $\mathrm{r}$ : individual repeatability; $\mathrm{c}^{2}{ }_{\text {plot }}$ : coefficient of determination of plot effects; $\mathrm{c}^{2}$ gm: coefficient of determination of genotype $\times$ measurement interaction effects; $\mathrm{c}^{2}$ perm: coefficient of determination of permanent effects; rgmsm: genotypic correlation through measurements.

Table 3. Coefficient of determination of repeatability $\left(\mathrm{R}^{2}\right)$, average heritability $\left(\mathrm{h}^{2}{ }_{\text {avg }}\right)$ accuracy of permanent phenotypic values based on $m$ years of evaluation $\left(\mathrm{A}_{\mathrm{cm}}\right)$, and efficiency of $\mathrm{m}$ evaluations, compared with the situation in which only one evaluation is performed $(\mathrm{Ef})$ for number of fruits, fruit weight, and total yield in full-sibling guava families evaluated in four harvests.

\begin{tabular}{ccccccccccccc}
\hline \multicolumn{4}{c}{ Number of fruits } & \multicolumn{4}{c}{ Fruit weight } & \multicolumn{5}{c}{ Total yield } \\
\hline $\mathrm{m}$ & $\mathrm{h}_{\text {avg }}^{2}$ & $\mathrm{R}^{2}$ & $\mathrm{~A}_{\mathrm{cm}}$ & $\mathrm{Ef}$ & $\mathrm{h}_{\text {avg }}$ & $\mathrm{R}^{2}$ & $\mathrm{~A}_{\mathrm{cm}}$ & $\mathrm{EF}$ & $\mathrm{h}_{\text {avg }}$ & $\mathrm{R}^{2}$ & $\mathrm{~A}_{\mathrm{cm}}$ & $\mathrm{EF}$ \\
\hline 1 & 0.08 & 0.26 & 0.29 & 1 & 0.05 & 0.14 & 0.22 & 0.77 & 0.11 & 0.24 & 0.33 & 1.15 \\
2 & 0.13 & 0.41 & 0.36 & 1.26 & 0.09 & 0.25 & 0.3 & 1.02 & 0.18 & 0.39 & 0.42 & 1.46 \\
3 & 0.16 & 0.51 & 0.41 & 1.4 & 0.12 & 0.33 & 0.34 & 1.18 & 0.22 & 0.49 & 0.47 & 1.63 \\
4 & 0.19 & 0.58 & 0.43 & 1.5 & 0.14 & 0.39 & 0.38 & 1.3 & 0.26 & 0.56 & 0.51 & 1.75 \\
5 & 0.2 & 0.64 & 0.45 & 1.57 & 0.16 & 0.45 & 0.4 & 1.39 & 0.28 & 0.61 & 0.53 & 1.83 \\
6 & 0.22 & 0.68 & 0.47 & 1.62 & 0.18 & 0.49 & 0.42 & 1.45 & 0.3 & 0.65 & 0.55 & 1.9 \\
7 & 0.23 & 0.71 & 0.48 & 1.65 & 0.19 & 0.53 & 0.44 & 1.51 & 0.32 & 0.69 & 0.56 & 1.94 \\
8 & 0.24 & 0.74 & 0.49 & 1.68 & 0.2 & 0.57 & 0.45 & 1.56 & 0.33 & 0.72 & 0.57 & 1.98 \\
9 & 0.24 & 0.76 & 0.49 & 1.71 & 0.21 & 0.59 & 0.46 & 1.59 & 0.34 & 0.74 & 0.58 & 2.01 \\
10 & 0.25 & 0.78 & 0.5 & 1.73 & 0.22 & 0.62 & 0.47 & 1.63 & 0.35 & 0.76 & 0.59 & 2.04 \\
11 & 0.26 & 0.79 & 0.51 & 1.75 & 0.23 & 0.64 & 0.48 & 1.66 & 0.36 & 0.78 & 0.6 & 2.06 \\
12 & 0.26 & 0.81 & 0.51 & 1.76 & 0.24 & 0.66 & 0.49 & 1.68 & 0.36 & 0.79 & 0.6 & 2.08 \\
\hline
\end{tabular}


Table 4. Order, predicted gain, and new mean for number of fruits, fruit weight, and total yield of the best full-sibling $P$. guajava progenies, evaluated in four harvests.

\begin{tabular}{ccccccc}
\hline \multicolumn{7}{c}{ Number of fruits } \\
\hline Order & Progeny & $\mathrm{g}$ & $\mathrm{u}+\mathrm{g}$ & Gain $(\%)$ & New mean & $\mathrm{u}+\mathrm{g}+\mathrm{gem}$ \\
\hline 1 & 8 & 16.3696 & 107.2893 & 18.01 & 107.2893 & 112.7474 \\
2 & 12 & 14.4116 & 105.3313 & 16.93 & 106.3103 & 110.1366 \\
3 & 17 & 8.3609 & 99.2806 & 14.35 & 103.967 & 102.0683 \\
4 & 2 & 7.381 & 98.3007 & 12.79 & 102.5505 & 100.7617 \\
5 & 10 & 6.1063 & 97.026 & 11.58 & 101.4456 & 99.062 \\
\hline & & & Fruit weight & & \\
\hline Order & Progeny & $\mathrm{g}$ & $\mathrm{u}+\mathrm{g}$ & Gain & New mean & $\mathrm{u}+\mathrm{g}+\mathrm{gem}$ \\
\hline 1 & 15 & 0.9875 & 188.0202 & 0.53 & 188.0202 & 194.0626 \\
2 & 13 & 0.7907 & 187.8234 & 0.48 & 187.9218 & 192.6616 \\
3 & 6 & 0.2895 & 187.3222 & 0.37 & 187.7219 & 189.0934 \\
4 & 1 & 0.2579 & 187.2906 & 0.31 & 187.6141 & 188.8686 \\
5 & 10 & 0.2074 & 187.2402 & 0.27 & 187.5393 & 188.5095 \\
\hline & & & Total yield & & & \\
\hline Order & Progeny & $\mathrm{g}$ & $\mathrm{u}+\mathrm{g}$ & Gain & New mean & $\mathrm{u}+\mathrm{g}+\mathrm{gem}$ \\
\hline 1 & 8 & 3518.697 & 19354.34 & 22.22 & 19354.34 & 20198.76 \\
2 & 12 & 2176.151 & 18011.8 & 17.98 & 18683.07 & 18534.03 \\
3 & 10 & 1758.934 & 17594.58 & 15.69 & 18320.24 & 18016.69 \\
\hline & 17 & 1126.112 & 16961.76 & 13.55 & 17980.62 & 17232 \\
\hline & 2 & 1052.282 & 16887.93 & 12.17 & 17762.08 & 17140.45 \\
\hline
\end{tabular}


Table 5. Analysis of phenotypic stability and adaptability in full-sibling P. guajava families.

\begin{tabular}{cccccc}
\hline \multicolumn{5}{c}{ Number of fruits } \\
\hline Order & Progeny & HMRPGV & HMRPGV*OM & RPGV & RPGV*OM \\
\hline 1 & 8 & 1.2215 & 111.0603 & 1.2411 & 112.8423 \\
2 & 12 & 1.1767 & 106.9838 & 1.2245 & 111.3318 \\
3 & 2 & 1.1079 & 100.73 & 1.1152 & 101.3968 \\
4 & 10 & 1.0782 & 98.0304 & 1.0946 & 99.5207 \\
5 & 17 & 1.0541 & 95.8398 & 1.0832 & 98.4838 \\
6 & 15 & 0.9247 & 84.0761 & 0.9335 & 84.8691 \\
7 & 1 & 0.8838 & 80.3518 & 0.8844 & 80.4133 \\
8 & 11 & 0.8209 & 74.6385 & 0.8304 & 75.5038 \\
9 & 6 & 0.7683 & 69.8576 & 0.8031 & 73.0209 \\
10 & 13 & 0.758 & 68.9179 & 0.7899 & 71.8146
\end{tabular}

\begin{tabular}{|c|c|c|c|c|c|}
\hline \multicolumn{6}{|c|}{ Fruit weight } \\
\hline Order & Progeny & HMRPGV & HMRPGV*OM & RPGV & $\mathrm{RPGV}^{*} \mathrm{OM}$ \\
\hline 1 & 15 & 1.0344 & 193.4696 & 1.0354 & 193.6547 \\
\hline 2 & 13 & 1.029 & 192.4477 & 1.0318 & 192.9766 \\
\hline 3 & 10 & 1.0092 & 188.7625 & 1.0106 & 189.0142 \\
\hline 4 & 1 & 1.0042 & 187.8101 & 1.007 & 188.349 \\
\hline 5 & 6 & 1.0029 & 187.567 & 1.0067 & 188.2793 \\
\hline 6 & 17 & 0.9975 & 186.5713 & 1.0028 & 187.5624 \\
\hline 7 & 11 & 0.9939 & 185.898 & 0.9948 & 186.0674 \\
\hline 8 & 8 & 0.981 & 183.4799 & 0.9837 & 183.9796 \\
\hline 9 & 2 & 0.9762 & 182.5734 & 0.9775 & 182.8271 \\
\hline 10 & 12 & 0.9471 & 177.1354 & 0.9497 & 177.6169 \\
\hline \multicolumn{6}{|c|}{ Total yield } \\
\hline Order & Progeny & HMRPGV & HMRPGV*OM & RPGV & $\mathrm{RPGV}^{*} \mathrm{OM}$ \\
\hline 1 & 8 & 1.2531 & 19843.87 & 1.2805 & 20277.14 \\
\hline 2 & 12 & 1.1556 & 18300.4 & 1.1806 & 18695.12 \\
\hline 3 & 10 & 1.1319 & 17925.06 & 1.1336 & 17951.61 \\
\hline 4 & 2 & 1.0723 & 16980.08 & 1.0768 & 17051.58 \\
\hline 5 & 17 & 1.0666 & 16890.34 & 1.0756 & 17032.24 \\
\hline 6 & 15 & 0.982 & 15550.13 & 0.9878 & 15642.12 \\
\hline 7 & 1 & 0.904 & 14315.77 & 0.9087 & 14390.42 \\
\hline 8 & 11 & 0.7788 & 12333.33 & 0.7954 & 12596.05 \\
\hline 9 & 6 & 0.7539 & 11938.15 & 0.7876 & 12471.62 \\
\hline 10 & 13 & 0.7489 & 11858.54 & 0.7735 & 12248.56 \\
\hline
\end{tabular}

HMRPGV: harmonic mean of the relative performance of genetic values; HMRPGV*OM: harmonic mean of the relative performance of genetic values multiplied by the overall mean; RPGV: relative performance of genotypic values; RPGV*OM: relative performance of genotypic values multiplied by the overall mean. 


\section{Acknowledgments}

The authors thank the Foundation for Research Support of the State of Rio de Janeiro (FAPERJ) for the fellowship grant and the Coordination of Improve- ment of Higher Education Personnel (CAPES) and the National Council for Scientific and Technological Development (CNPq) for the financial support for this experiment.

\section{References}

DHARA, P.; PATEL, N.L.; TANVEER, A.; APEKSHA, P.; KUMAR, V. 2016. Effect of Pre-Cooling Packaging Material on Chemical and Sensory Quality of Guava Fruits [Psidium guajava (Linn.)] Cv Allahabad Safeda. Environment \& Ecology, 35:64-69.

FIGUEIREDO, A.G.; VON PINHO, R.G.; SILVA, H.D.; BALESTRE, M. 2015. Application of mixed models for evaluating stability and adaptability of maize using unbalanced data. Euphytica, 202(3):393-409, 2015.

IMAI, A.; KUNIGA, T.; YOSHIOKA, T.; NONAKA, K.; MITANI, N.; FUKAMACHI, H.; HAYASHI, T. 2016. Evaluation of the best linear unbiased prediction method for breeding values of fruit-quality traits in citrus. Tree Genetics \& Genomes, 12(6):119.

KANWAL, N.; RANDHAWA, M.A.; IQBAL, Z. 2016. A Review of Production, Losses and Processing Technologies of Guava. Asian Journal of Agriculture and Food Sciences, 4:2321-1571.

KAREEM, A.; JASKANI, M.J.; FATIMA, B.; SADIA, B. 2013.Clonal multiplication of guava through softwood cuttings under mist conditions. Pakistan Journal of Agricultural Sciences, 50:23-27.

LAVIOLA, B.G.; OLIVEIRA, A.M.C.; BHERING, L.L.; ALVES, A.A.; ROCHA, R.B.; GOMES, B.E.L.; CRUZ, C. 2013. Estimates of repeatability coeficientes and selection gain sin Jatropha indicate that higher cumulative genetic gains can be obtained by relaxing the degree of certainty in predicting the best families. Crops and Products, 51:70-76.

LOPES, V.R.; BESPALHOK FILHO, J.C.; DAROS, E.; OLIVEIRA, A.O.; GUERRA, E.P. 2014. Multivariate genetic divergence among sugarcane clones by multivariate analysis associated with mixed models. Semina: Ciências Agrárias, 35(1):125-134.

MAIA, M.C.C.; RESENDE, M.D.V.; PAIVA, J.R.; CAVALCANTI, J.J.V.; MOURA BARROS, L. 2009. Simultaneous selection for genotypic production, adaptability, and stability in cashew clones by mixed models. Pesquisa Agropecuária Tropical, 39:43-50.

QUINTAL, S.S.R.; VIANA, A.P.; CAMPOS, B.M.; VIVAS, M.; AMARAL JÚNIOR, A.T. 2017. Selection via mixed models in segregating guava families based on yield and quality traits. Revista Brasileira de Fruticultura, 39(2):e-866.

RESENDE, M.D.V. Software Selegen-REML/BLUP: a useful tool for plant breeding. 2016. Crop Breeding and Applied Biotechnology, 16: 330 -339.

ROCHA, L.F.; CAVALCANTE, L.F.; NUNES, J.C.; DE LUNA SOUTO, A.G.; CAVALCANTE, A.C.P. CAVALCANTE, Í.H.L.; PEREIRA, W. E. 2016. Fruit production and quality of guava 'Paluma' as a function of humic substances and soil mulching. African Journal of Biotechnology, 15(36), 19621969.

RODRIGUES, H.S.; CRUZ, C.D.; MACÊDO, J.L.V.; RESENDE, M.D.V.; LOPES, R.; BORÉM, A. 2017. Genetic variability and progeny selection of peach palm via mixed models (REML/BLUP). Acta Scientiarum Agronomy, 39(2):165-173. 
SANCHÉZ, C.F.B.; ALVES, R.S.; GARCIA, A.D.P.; TEODORO, P.E.; PEIXOTO, L.A.; SILVA, L.A.; RESENDE, M.D.V. 2017. Estimates of repeatability coefficients and the number of the optimum measure to select superior genotypes in Annona muricate L. Genetics and Molecular Research: 16(3).

SANTOS, E.A.; VIANA, A.P.; FREITAS, J.C.O.; RODRIGUES, D.L.; FERREIRA, R.T.; PAIVA, C.L.; SOUZA, M.M. 2015. Genotype selection by REML/BLUP methodology in a segregating population from an interspecific Passiflora spp. crossing. Euphytica, 204:1-11.

TORRES, F.E.; TEODORO, P.E.; RODRIGUES, E.V.; SANTOS, A.; CORRÊA, A. M.; CECCON, G. 2016. Simultaneous selection for cowpea (Vigna unguiculata L.) genotypes with adaptability and yield stability using mixed models. Genetics and Molecular Research, 15(2).

VISMARA, E.S.; MEHTÄTALO, L.; BATISTA, J.L.F. 2015.Linear mixed-effects models and calibration applied to volume models in two rotations of Eucalyptus grandis plantations. Canadian Journal of Forest Research, 46(1):132-141. 